\title{
Study on Determining the Vertical Wheel-Rail Force by Measuring Rail Displacement
}

\author{
LIU Keda \\ Institute of Rail Transit \\ Tongji University \\ Shanghai, China \\ 1237366@qq.com
}

\author{
LIU Xin \\ The Third Railway Survey and Design Institute Group \\ Corporation \\ TianJin, China \\ 691309375@qq.com
}

\begin{abstract}
Determining the vertical wheel-rail force by measuring rail displacement is approved to be feasible in this paper. Wheel-rail force data is collected following the common way firstly, i.e. strain gauge is pasted on the rail to measure the strain. During the test, different vehicle running speeds through the measuring point are considered. In the same time, rail displacement data is measured by the laser ranging technology. The measured rail displacement data are used in the finite element analyzing process in order to calculate the corresponding vertical wheel-rail force. The wheel-rail force is calculated based on Winkler Beam theory. Calculated vertical wheel-rail force through FEA by using the tested rail displacement and the measured vertical wheelrail force are subsequently compared. Calculated vertical wheel-rail force by using the measured rail displacement can meet the tested vertical wheel-rail force via strain gauge rather well, indicating that the measuring method of vertical wheel-rail force proposed in the current paper is reasonable. It can meet the accuracy requirements of the practical engineering from both analytical and numerical perspective.
\end{abstract}

Keywords-Vertical Wheel-rail force; rail displacement; measure; model; comparison

\section{INTRODUCTION}

Force between rail and wheel often happens in three directions, vertical, lateral and longitudinal [1-2]. If the rail-wheel force exceeds the limit range, it will aggravate the structural vibration and the rail-wheel wear, reduce its service life, and will lead to the derailment of vehicle. Thus wheel-rail force detection is very important for the safety and comfort of the train running.

The most common way of measuring rail-wheel force at present is by using strain gauges on the rail and the wheel set[3-4]. The wheelset measurement attaches the strain gauge on the wheelset to get the rail/wheel force through the distortion of the wheel. The rail measurement chooses the specified section and paste the strain gauge on it to obtain the rail/wheel force [5]. Compared with the method of measuring force on the rail, the wheelset method can monitor the rail/wheel force continuously through the measurement of finite point on the spoke, but this method needs to replace common wheel into test wheel in preliminary work which is unrealistic when monitor all operating vehicles. The rail measurement solves the defects. Continuous output algorithm is also proposed to obtain continuous value on the rail [6-7]. While pasting strain gauge on the rail is still a complex work, it not only need a full-polished rail but also a lot of manpower, artificial errors in the process will also make the unsatisfactory results.Besides, the testing process is vulnerable to electromagnetic interference and the strain gauge are normally not recycled. However, laser ranging technology is highly precise and stable, the rail displacement can be easily measured by using which. This paper proposes a method to obtain the vertical wheel-rail force by measuring the displacement of the rail and try to demonstrate the feasibility of this method [8]. Using laser ranging technology measures the displacement of rail. Using continuous elastic beam model and elastic point support beam model calculates the wheel/rail force. Numerical modeling process is also proposed in this paper, aiming at providing a new method to determine the railwheel force.

\section{FASTENER STATIC STIFFNESS TEST}

Testing the fastener stiffness by using Schenck machine. Before the test, make all the component and equipment stay in test experiment for 24 hours, torque $300 \mathrm{Nm} \pm 50 \mathrm{Nm}$ is used to tighten supporting plate and

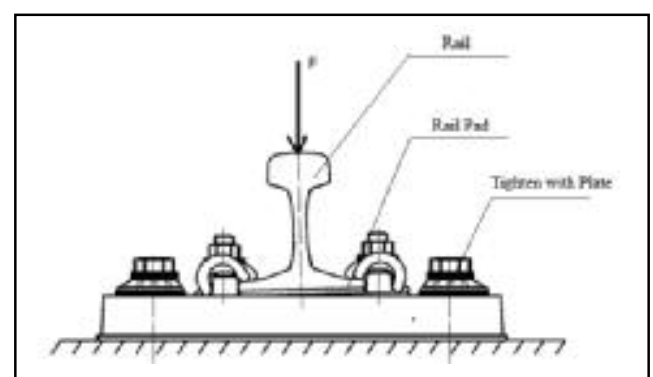

test pieces. Placing order of vertical stiffness test: supporting plate, testing component, rail pad, shorting rail. As shown in Fig .1 and Fig .2. Using Force-Displacement curve calculates the vertical static stiffness of fastener.

Figure 1. Loading method 


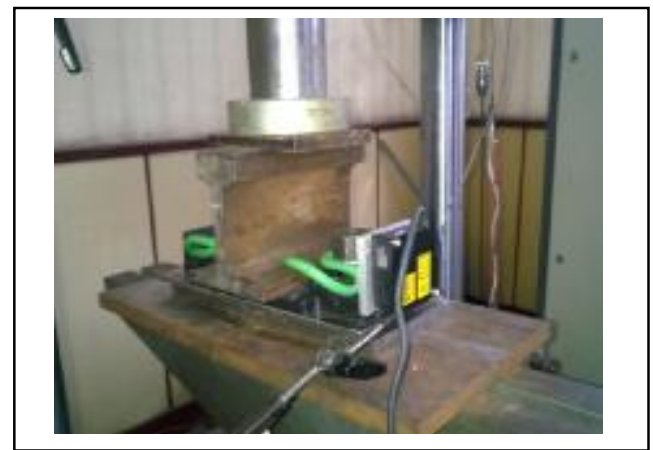

Figure 2. Loading scene

\section{MEASURING RaIL DiSPlaCEMENT By LASER RANGING TECHNOLOGY}

In order to obtain the rail displacement, the sensor is used to carry out the rail displacement test on the Rail Transit Line of Tongji University. The test spot is a straight flat track line. Space between fastener is $600 \mathrm{~mm}$, the thickness of roadbed is $610 \mathrm{~mm}$; rail model is $60 \mathrm{~kg} / \mathrm{m}$. The testline is $30 \mathrm{~m}$ long of ballastless track, mainly basing on the theory that test length should not less than a single test vehicle length. The laser displacement sensor is arranged on the wheel-rail force measuring position, and the vertical displacement is measured, the measuring points are arranged on the outside of the two rails. Setting up $1,2,3$,and 4 , four points from one side to another, as shown in Fig. 2 and Fig .3 and Fig .4.Recording the measuring point value when the vehicle running under the speed of $20 \mathrm{~km} / \mathrm{h}, 30 \mathrm{~km} / \mathrm{h}, 40 \mathrm{~km} / \mathrm{h}$ both departure and return.

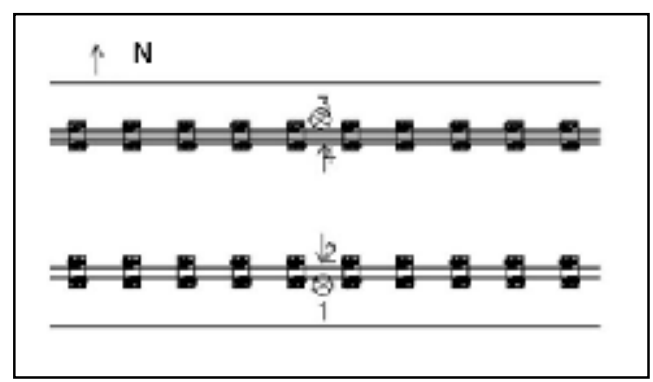

Figure 3. Measuring point arrangement

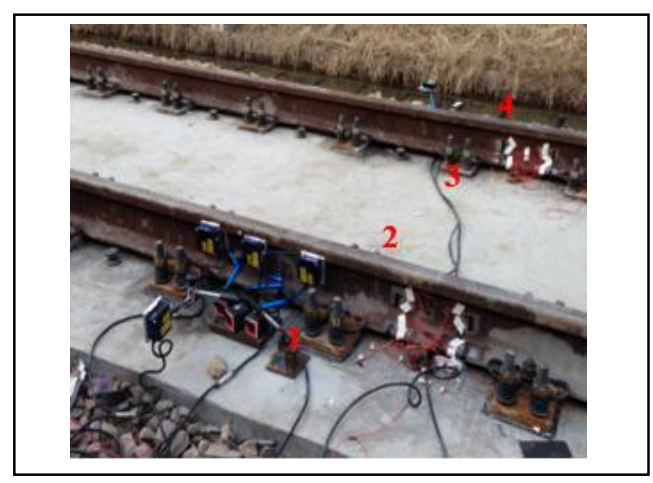

Figure 4. Measuring scene

\section{THEORETICAL ANALYSIS AND CALCULATION}

\section{A. The relationship verification of rail displacement and} load in continuous elastic beam model

The system of rail and fastener can be simplified as continuous beam structure, and we intercept one section, as shown in Fig .5.

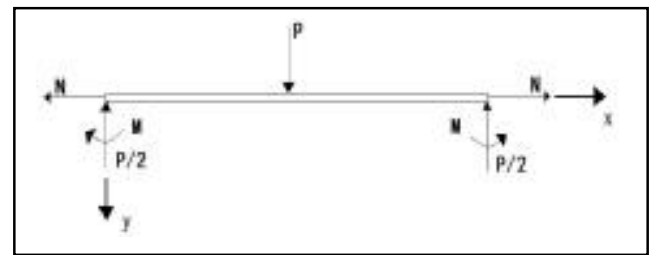

Figure 5. Rail force analysis

The span is affected by concentrated load P. Endpoint bending moment is $\mathrm{M}$; Temperature stress is N; Flexural rigidity is EI; Flexural rigidity of end portion is $\mathrm{H}$. According to the theory of material mechanics, the equation of flexibility is as follows:

$$
\mathrm{EIy}^{\prime \prime}=\mathrm{Ny}-\frac{P}{2} x+M
$$

Supposing $\mathrm{K}=\sqrt{\frac{N}{E I}}$, general solution of equation is

$$
\mathrm{y}=C_{1} e^{K x}+C_{2} e^{-K x}+\frac{P}{2 N} x-\frac{M}{N}
$$

Boundary conditions is $\mathrm{y}(0)=0$;

$\mathrm{y}^{\prime}\left(\frac{L}{2}\right)=0 ; y^{\prime}(0) H=M$. It can be obtained by the boundary conditions:

$$
\left[\begin{array}{ccc}
1 & 1 & -\frac{1}{N} \\
K e^{\frac{K L}{2}} & -K e^{-\frac{K L}{2}} & 0 \\
K & -K & -\frac{1}{H}
\end{array}\right]
$$

Solutions of equations are

$$
\begin{gathered}
C_{1}=-\frac{P}{2 K N} \frac{N+H K\left(1-e^{-\frac{K L}{2}}\right)}{(N-H K) e^{-\frac{K L}{2}}+(N+H K) e^{\frac{K L}{2}}} \\
C_{2}=\frac{P}{2 K N} \frac{N+H K\left(e^{\frac{K L}{2}}-1\right)}{(N-H K) e^{-\frac{K L}{2}}+(N+H K) e^{\frac{K L}{2}}} \\
\mathrm{M}=\frac{P H}{2} \frac{e^{\frac{K L}{2}}+e^{-\frac{K L}{2}}-1}{(N-H K) e^{-\frac{K L}{2}}+(N+H K) e^{\frac{K L}{2}}}
\end{gathered}
$$

We can obtain deflection equation of $\operatorname{span} \mathrm{x}=\frac{L}{2}$ 
$\delta=\mathrm{y}\left(\frac{L}{2}\right)=\frac{P H}{2} \frac{2 H K\left(2-e^{\frac{K L}{2}}-e^{-\frac{K L}{2}}\right)+N\left(e^{-\frac{K L}{2}}-e^{\frac{K L}{2}}\right)}{(N-H K) e^{-\frac{K L}{2}}+(N+H K) e^{\frac{K L}{2}}}+\frac{P L}{4 N}(4)$

The variables affecting span displacement are $\mathrm{P}, \mathrm{N}, \mathrm{H}$. Supposing $\mathrm{H}=50 \mathrm{kN} / \mathrm{mm}$, the influence of parameters $\mathrm{P}$ and $\mathrm{N}$ on deflection is shown in Fig .6. The value $\delta / \mathrm{P}$ reflects the linear relationship of concentrated load and deflection.

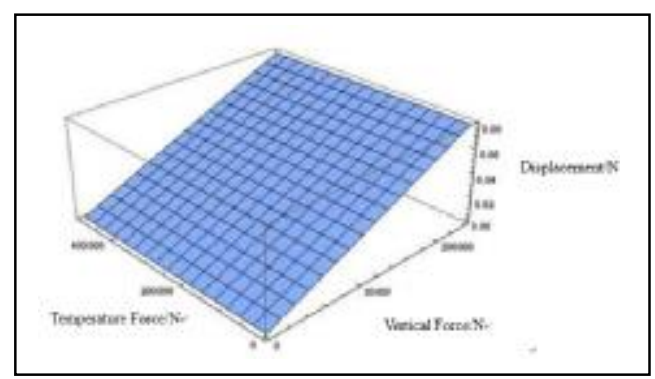

Figure 6. Temperature influence on vertical deflection

As can be seen from Figure 6, temperature stress $\mathrm{N}$ has little influence on deflection. If we don't consider temperature stress $\mathrm{N}$, span deflection formula is as follows:

$$
\delta=\mathrm{y}\left(\frac{L}{2}\right)=-\frac{P L^{3}}{96 E I}+\frac{H L^{4} P+4 E I P L^{3}}{8 E I(8 H L+16 E I)}
$$

Span deflection can be defined as $\delta=\frac{P L^{3}}{\lambda E I}, \lambda$ ranging between 48-96.

It can be ignored that temperature stress' influence on span deflection when the load is applied. Without considering temperature stress, the relationship of span displacement and concentrated load is a linear relationship.

\section{B. The vertical wheel-rail force calculation based on continuous elastic supporting beam model}

With the influence of rail flexural rigidity based on continuous elastic supporting beam model, Sleepers for the rail support can be considered as continuous support[9]. As shown in Fig .7. The stiffness of rail is D; the distance between two sleepers is d; Distributed force of unit sink required by rail is $\mathrm{u}=\mathrm{D} / \mathrm{d}$.

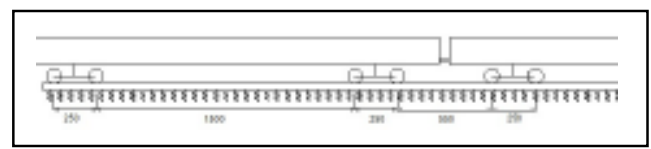

Figure 7. Rail continuous support model

The rail point where distance from the measuring point $\mathrm{O}$ is $\mathrm{L}$ is affected by vertical load $\mathrm{P}$ which is $\mathrm{P}$. the Displacement of measuring point $\mathrm{O}$ affected by vertical load $\mathrm{P}$ is shown as following formula:

$$
\delta=\frac{k}{2 u} P\left\{e^{-k L}(\cos k L+\sin k L)\right\}
$$

$\mathrm{k}=\sqrt[4]{\frac{u}{4 E I}}$ representsthe vertical load on the measuring point; $\mathrm{x}$ represents the horizontal distance of measuring point and wheel; $\delta$ represents deflection of measuring point. Because the displacement and load appears a linear relationship, a plurality of deflection on vertical forces generated can be superimposed computing. Deflection measuring point $\mathrm{O}$ for rail can be simplified as sum of several deflection. Through analysis and calculation, it can be ignored that the influence of the measuring point when the distance of position of applied force and measuring point is more than 2 meters. Therefore, the deflection calculated can take no consider about the impact of the bogie adjacent measuring points. When solving rail displacement, we just need to consider the impact on the two wheels of a bogie, which one wheel lies in measuring point $\mathrm{O}$ and the other one is distance $\mathrm{L}$ apart from that.

$$
\delta=\frac{k}{2 u} P\left\{e^{-k L}(\cos k L+\sin k L)+1\right\}
$$

\section{Finite element model calculation}

Based on the elastic point-support model, the rail structure is described as a series of separate spacing sleeper of discrete elastic damping point-support system [10], a track static model is established by using ABAQUS, as shown in Fig.8, the fastening system is simulated with spring elements. Inputting the field test measurement value in this model and then calculate the wheel-rail force.

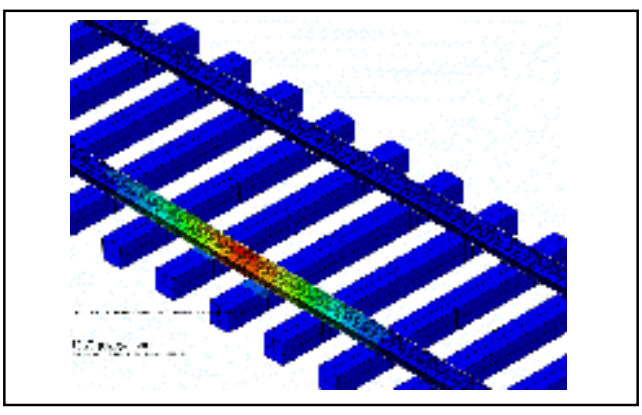

Figure 8. Results of FEA model calculation

\section{COMPARISON ANALYSIS OF WHEEL-RAIL FORCE CALCULATION AFTER THE TEXT EDIT HAS BEEN}

Equation (6) can be used to calculate the stiffness and the displacement of the rail.

TABLE I. VERTICAL RAIL-WHEEL FORCE CALCULATION

\begin{tabular}{|c|c|c|c|c|}
\hline Speed & $\begin{array}{c}\text { Average } \\
\text { displacement }\end{array}$ & $\begin{array}{c}\text { Rail- } \\
\text { wheel } \\
\text { force }\end{array}$ & $\begin{array}{c}\text { Theoretical } \\
\text { calculation }\end{array}$ & $\begin{array}{c}\text { FEA model } \\
\text { calculation }\end{array}$ \\
\hline $\mathbf{2 0 k m} / \mathbf{h}$ & $0.646669 \mathrm{~mm}$ & $57843 \mathrm{~N}$ & $58702 \mathrm{~N}$ & $59208 \mathrm{~N}$ \\
\hline $\mathbf{3 0} \mathbf{k m} / \mathbf{h}$ & $0.637084 \mathrm{~mm}$ & $59492 \mathrm{~N}$ & $57831 \mathrm{~N}$ & $59992 \mathrm{~N}$ \\
\hline $\mathbf{4 0} \mathbf{k m} / \mathbf{h}$ & $0.642981 \mathrm{~mm}$ & $57035 \mathrm{~N}$ & $58367 \mathrm{~N}$ & $58045 \mathrm{~N}$ \\
\hline
\end{tabular}

From above value we can see, in continuous elastic support beam model, the average error of wheel-rail force between calculated values and measured values is $2.2 \%$, in finite element model under the elastic point-support beam theory, the average error of wheel-rail force between calculated values and measured values is $1.6 \%$.It proves that the difference between theoretical value and measured value is small, itcan meet the accuracy requirements.

\section{CONCLUSIONS}

There is correspondent relationship between the vertical displacement and wheel-rail force, if the fastener 
stiffness is known, laser ranging technology can be used to measure the vertical displacement in the middle span, then the continuous elastic support beam model or the elastic point-support model can be used to obtain the vertical railwheel force. Calculated vertical wheel-rail force by using the measured rail displacement can meet the tested vertical wheel-rail force via strain gauge rather well, indicating that the measuring method of vertical wheel-rail force proposed in the current paper is reasonable. It can meet the accuracy requirements of the practical engineering from both analytical and numerical perspective.

\section{REFERENCES}

[1] LIU Jianxin. YI Ming-hui, WANG Kaiyun. Characteristic of dynamic interaction between wheel and rail due to wheel tread flat on heavy haul railway [J] .Journal of Traffic and Transportation Engineering, 2010, 10(3): 52-56.

[2] CHEN Jianzheng .Study on theory of onboard measurement of w heel and rail forces [D]. Chengdu:Southwest Jiaotong University , 2008 .
[3] Akira, Matsumoto, Qu Wenqiang. A New Method to Measure the Wheel-Rail Force[J]. Foreign Rolling Stock, , 2013, 50(4).

[4] The research on measurement of wheel rail force based on axle stree instrumented wheelset [D]. Chengdu: Southwest Jiaotong University, 2014.

[5] Heavy haul railway train safety monitoring technology based on the laser sensor [J].Engineering Sciences, 2009, 11(10):61-66.

[6] LI Yifan, LIU Jianxin, WANG Kaiyun, etal. Wheel/rail force continuous exporting algorithm of instrument ted rail [J]. Journal of Traffic and Transportation Engineering,2011, 11(4) : 36-40.

[7] Zhao Guotang. Method of determining the stiffness of railway. China Academy of Railway Sciences, 2005, 26(1):1-6.

[8] JIN Xin, JIN Xincan, GONG Ming, MA Lijun. Wheel-rail force identification and analysis based on wheelset dynamic stress testing[J]. Journal of Beijing Jiaotong University. 2012, 36(4):173177.

[9] Chen Xiufang. Rail Engineering [M]. Beijing: China Building Industry Press, 2004:172-179.

[10] Study on methods for continuous measurement and indentification of the vertical interaction between wheel/rail [D]. Chengdu: Southwest Jiaotong University, 2007. 